\title{
The Analysis of Mode and Path Selection of the Equalization of Public Sports Services
}

\author{
Ling Yang \\ Xi'an International University, Xi'an 710077, China
}

Keywords: national fitness; Public sports services; Equalization; Mode selection; Path analysis.

\begin{abstract}
With the development of China's economy and the improvement of people's living standard, people's demand for fitness is increasing. Therefore, the national and sports departments put forward the concept of national fitness. With the continuous implementation of the concept, the national fitness public sports service, which provides sufficient impetus for the development of the national fitness movement, is gradually strengthening, However, public sports service is still an unequal, which affects the development of national fitness movement in China. To make the sports fitness products and services such as the allocation of public resources more reasonable and close the gap between regions and between urban and rural areas, we should establish and improve the basic standards, so it is imperative to equalize national fitness public sports service. This paper will explore the mode selection and path of equalization of public sports services by analyzing the basic content of public sports service and equalization.
\end{abstract}

\section{Introduction}

The national fitness campaign is the requirements of the country, and it is also accord with the present living standards of people and the economic development in our country. It has a great effect to improve the physical quality and enrich people's life. Therefore, to promote the development of this sport, sports departments have increased their input in public sports facilities and public sports services to meet the needs of people's living and fitness. However, due to the current situation of our country, the public sports service has not been fully equal, and this inequality will seriously affect the promotion of the national fitness campaign and even cause social problems. Therefore, in response to this phenomenon, we should adjust the public service and try our best to equalize it. We should reduce the differences between urban and rural areas and between urban and rural areas and promote the development and improvement of basic service standards. Therefore, it is necessary to actively explore the mode and path of equalization of public sports services.

\section{The Basic Content of Public Sports Service and Equalization}

The national fitness public sports service refers to the provision of sports services or products according to the economic development level of our country, based on the needs of the people's sports services. In this process, although the regional economic development situation in our country is different, but the national fitness public sports service goal is to provide basic sports products or services for all members of society. We should consider the needs of the people when providing public sports services for the public. The needs of the people are to achieve health and recreation through exercise.

The meaning of equalization of public sports services for the whole people have tow aspect. One of which is to ensure that citizens enjoy physical fitness services, is a fundamental right of the people. The other is that people have equal rights in fitness opportunities and services. Although our country has a large population and we also have great differences between each other. But people have the same right to enjoy fitness opportunities and services. The equalization of public sports services is not only the average of supply, but also a method that targeted allocation of public sports resources based on economic development. 


\section{The Problems of Equalization of Public Sports Services in China}

\subsection{Regional Differentiation}

There are differences in economic development in different regions of our country, which is a serious obstacle to equalization of public sports services. Therefore, the public sports service should be different in different regions. China has a vast territory. In general, the development level of the east is higher than that of the west, especially the economic development level of the southeast coastal zone. We have recognized the differences between regions and have taken active measures to compensate and balance them, but the differences remain. This is an important reason for the uneven public sports service.

There is a huge difference in our investment in sports in the east and west. In many surveys, many people do not exercise because of lack of sports facilities and sports venues. This is a factor that seriously affects the movement of the national fitness movement.

\subsection{Differentiation between Urban and Rural Areas.}

Urban and rural difference is an inevitable problem in the development of human society. Especially in the current stage of economic development in China, the economic level between urban and rural areas is quite different. How to coordinate the differences between urban and rural areas is a key issue that we must consider in the process of social development. The establishment of binary structure makes the difference between urban and rural areas more and more different, especially in per capita income.

Such economic development has led to the difference in the public sports service between urban and rural residents. Many rural areas have no basic physical fitness equipment and facilities. Moreover, the quality of sports service also varies greatly. The rural population accounts for a large part of the population in our country, but the supply of sports facilities and sports venues rarely, such obvious differences in public sports service is a problem need to be solved in national fitness public sports service equalization.

\subsection{Lack of Equalization Standards for Public Sports Services for all Citizens}

In the process of equalization of public sports services, we do not have clear equalization standards. This has hampered us, especially in the allocation of public sports services. Due to the lack of content standards, there will be many inequalities. Such as the standard of sports facilities, sports ground standard and so on, these all have no clear rules. In the process of the national fitness public sports service equalization, it is difficult to find the basis of equal, the standards now are lack of rationality and scientific nature.

\section{The Mode Selection of the Equalization of Public Sports Services for the Whole People.}

\subsection{Equalization of Public Finance and Public Services Mode}

The dominant role of public finance can promote the equalization of public sports services. Only by ensuring the reasonable expenditure of public finance can the public service needs of members of society be satisfied. Once the public needs are met, the public finances will be balanced. The two complements contribute to each other and promote the public sports service and equalization of national fitness. Equalization of fiscal revenue and expenditure, equalization of fiscal revenue and equal demand for fiscal expenditure are the main contents of equalization of public finance.

\subsection{Public Service Standardization Mode and the Minimum Equity of Basic Public Services Mode.}

The public service standardization mode is that government unify the standards for facilities and services for public services. In this mode, public services are supplied in accordance with the relevant standards and can be reasonably implemented in areas with a smaller scope.

The minimum fair of basic public services mode enables people to enjoy more equal access to public services. This model can effectively combine funds safeguard is one of the features and functions of the government, the spillover effects for equivalence, location of neutral, correct, concentration and so on have very strong redistribution adjustment. The equalization of public 
finance, is one of the pattern of the national fitness public sports service equalization, but equal public services as the realization of the national fitness public sports service equalization condition appears more important.

\subsection{Advantages of the Minimum Equity of Basic Public Services Mode.}

1. It is in line with China's basic national conditions. There is a large gap between urban and rural areas in China, and the development of sports industry in China is not very perfect. Such basic national conditions make the basic public service minimum equity model our best choice. The establishment of the minimum standard is conducive to the convenience brought by public service in the backward areas of China. Higher standards or uniform standards may result in the loss of access to public sports services in these areas, leading to the emergence and social problems of inequality in our country. The mandatory minimum standard is consistent with the basic national conditions of China's development level.

2. It is benefit to the construction of service-oriented government and harmonious society. For public sports service, every citizen has the right, so the minimum equity of basic public service mode to protect the rights of the masses of the people's basic mode, which is the key links of our government in building a service-oriented government. the minimum equity of basic public service mode can avoid the unequal because of public sports service social problems, can effectively guarantee the steady development of society, is an important means of building a harmonious society.

3. It conforms to the trend of gradual development. In our country's public service and social economy development in the process of gradual development trends, this trend is beneficial to eliminate risk factors in the development process, to ensure the stability and sustainability of development. The minimum equity of basic public service mode, can in maximum extent, and the gradual development trend of public service and social economy, ensure the steady development of our economy and public services. Before to avoid blindness in economic development plays an important role, in the process of economic development and public services, according to the actual situation to improve standards can be reduced to the improvement of standard of risk factors, to ensure that our country economy and social stability.

\section{The Path Analysis of the Equalization of Public Sports Services for the Whole People.}

\subsection{Establish a Comprehensive System of Equalization of Public Sports Services for All People.}

The scope and content of equalization design of public sports services for the whole people are relatively extensive, including the departments, regions, people, time and so on. In dealing with national fitness public sports service equalization, we should fully consider various factors, the comprehensive analysis of global control, improve the national fitness public sports service equalization. Therefore, we should establish a sound system, reasonably manage the equalization of public sports services for all people and speed up the equalization of public sports services for all. It is an important link to establish the perfect management system and the key to realize the equalization of public sports service. So, we need to know the public sports service market demand, make the right sports resource allocation decisions based on rational analysis, including sports resources equalization measures and evaluation and so on, these are an important factor of security system perfect. For the operating mechanism of the national fitness public sports service equalization system, also must carry on the corresponding improvement, such as the amount of public finance management, perfecting the operation way and so on, to promote the improvement of the national fitness public sports service equalization system.

\subsection{Coordinate the Differences Between Urban and Rural Areas.}

Differences between urban and rural and differences in regional economic development level is an important factor that influence public sports service equalization. So, we need to consider and regional differences between urban and rural areas, formulate measures to coordinate difference between urban and rural areas, to implement public sports service equalization. Financial support and policy support can alleviate the gap between the public sports service and public sports service. With the development of society, we will eventually eliminate the gap. In coordinating the differences 
between urban and rural areas, attention should be paid to not being too aggressive, resulting in the weakness of the other side's power or rights. To harmonize the differences between the public sports service in urban and rural areas can make public sports services more equal, which is an important measure to consider every legal civil right. Handle between the urban and rural areas of differences between the national fitness public sports service, help narrow the gap between urban and rural areas of our country, to safeguard social stability and economic development of our country has a crucial role in [2].

\subsection{The Standard of Service Content Shall be Clearly Defined.}

The standard of equalization of public sports services is a problem we need to consider first. If there is no clear standard for reference, we will be difficult to seize the key work, and we have no way to check the results. It is not conducive to the realization of public sports service equalization. So, the standard of the service content should be clear, we should ensure that the public sports service equalization documentaries are able to work continuously in accordance with the relevant standards at ordinary times. It should be more conducive to improve work efficiency, avoid the blindness of public sports service equalization. The development level of our economy and the demand of our people for public service should be the reference basis for the establishment of the standard of equalization of public sports services. Only when we fully understand the needs of public services and the level of national economic development, the work of equalization of public sports services can be more clearly defined.

\subsection{Transformation of Public Service Functions}

In the process of equalization of public sports services, the government plays a vital role in the management of public sports services. The government should allocate public resources reasonably and ensure the rationality and scientificity of public sports service according to the needs of public service and the level of economic development. But many department did not attach enough importance to its public service functions of government, resulting in many public service works can't satisfy people's demand. And many local governments public service function is not clear, which caused work chaos, affected the work progress of public sports service equalization. Therefore, it is a crucial step to transform the function of government public service. In the process of transformation of government's public service function, the government must first clear the basic concept of public service, secondly to know public sports service, this is very important to ensure the implementation of public sports service equalization [3].

\section{Conclusion}

Public sports service equalization is an important work, the model we can choose includes the public finance and public service equalization mode, public service standardized mode and the minimum equity of basic public services mode.

According to the basic national conditions of China and the requirements of building a harmonious society, the minimum equity of basic public services mode is an optimal choice at present. In the path choice of public sports service equalization, there are four effective ways: to establish a perfect equalization system for public sports services, to coordinate the differences between urban and rural areas, to define the standards of service content and to promote the transformation of public service functions.

\section{Acknowledgements}

Fund project: Xi'an 2017 social science planning fund, research on the equalization demand path of community sports public service resources in Xi 'an city, project no.: 17 IN20. 


\section{References}

[1]. Zhang Di. Study on the equalization of public sports services in small and medium-sized cities -based on the survey of Tongling city in national demonstration city [J]. Sport,2017(12):128-129+105.

[2]. Zhong Hua. equal public sports service supply path. [A] of the state general administration of sports, sports science society of China. Proceedings of the third annual scientific conference [C]. State general administration of sports, sports science society of China: 2014-2.

[3]. Tang Jilan, Xu Tian, Guo Quan. Mode selection and path exploration of equalization of public sports services [J]. Journal of Nanjing institute of physical education (social sciences edition),2010,24(05):80-84. 